\title{
JoÃo PEDRo PoRTo a FUNDO, NA RAIZ DO HUMANO
}

\section{JOÃO PEDRO PORTO IN DEPTH, AT THE ROOT OF THE HUMAN}

http://dx.doi.org/10.11606/issn.2175-3180.v13i25p279-293

Susana L. M. Antunes ${ }^{\mathrm{I}}$

\section{RESUMO}

Entrevista com o escritor açoriano João Pedro Porto que este ano assinala uma década desde que publicou o seu primeiro livro. Para além de escritor, João Pedro Porto exerce a profissão de psicoterapeuta.

\section{PALAVRAS-CHAVE}

João Pedro Porto; Literatura; Psicoterapia.

\section{ABSTRACT}

Interview with Azorean writer João Pedro Porto in the year that marks a decade since he published his first book. In addition to being a writer, João Pedro Porto is a psychotherapist.

\section{KEYWORDS}

João Pedro Porto; Literature; Psychotherapy.

\section{O PRIMEIRO ENCONTRO (EM BREVIDADE)}

Conheci o João Pedro Porto há mais de vinte anos. Na altura, eu estava a estagiar na Escola Secundária Domingos Rebelo, Ponta Delgada, São Miguel - Açores, para concluir a minha licenciatura em Línguas e Literaturas Modernas - Português e Francês, via ensino. O João Pedro Porto era aluno de Português de uma colega minha. Ele deveria ter uns 16 anos. Como estávamos todas a estagiar, era obrigatório assistirmos às aulas umas das outras para partilharmos opiniões com as supervisoras.

No entanto, fora destas formalidades, falávamos sobre os nossos alunos. Afinal, era a nossa primeira experiência no ensino e o nosso entusiasmo era o entusiasmo inerente a todas "as primeiras vezes" da vida. Foi durante estes momentos que a perspicácia e a inteligência calada de João Pedro Porto começou a ser notada pela professora e por todas nós. Na

\footnotetext{
I Universidade de Wisconsin, Milwaukee, EUA.
} 
nossa inexperiência, achávamos que aquele aluno era excecional. E era-o, na verdade.

\section{O REENCONTRO ALÉM-MARES}

A vida encaminhou-nos, a mim e às minhas colegas de então, para percursos diferentes entre ilhas e além-ilhas. Sempre de regresso às ilhas açorianas em peregrinação anual, fui-me mantendo a elas ligada em todas as vertentes que, à distância, são possíveis. Num dos meus momentos de aproximação à literatura açoriana, começo a dar-me conta de um jovem escritor micaelense: João Pedro Porto. O nome, passados mais de vinte anos, não me soava, mas havia qualquer coisa de inexplicável - suponho, agora, que terá sido uma espécie de bom presságio. Comecei a ler, a procurar fotografias e, um dia, senti o baque de uma certeza não confirmada. Tudo me levava a crer que o escritor açoriano de sucesso João Pedro Porto era o jovem de 16 anos daquele tempo... vi e revi as suas fotografias nas contracapas dos livros e achava que o olhar era exatamente o mesmo daquele jovem de 16 anos. Por linhas mais ou menos travessas, cheguei ao seu email para organizar um Caderno Açoriano dedicado à sua produção escrita. Começamo-nos a corresponder por email para a organização dos materiais necessários. E, um dia, não resisti; perguntei-lhe se ele não era o aluno de português... expliquei-lhe quem eu era e o João Pedro reconheceume. O resultado do reencontro é o que a entrevista ilustra.

SUSANA L. M. ANTUNES: Quem é o João Pedro Porto?

JOÃO PEDRO PORTO: Não há pergunta mais redutora do que essa, porque nos reduz a uma pessoa apenas, quando talvez tenhamos multitudes dentro de nós. E temos a tendência de confundir o que nos define com verbos, com o que fazemos, ou de onde e de quem vimos. Ainda assim, se me visse de braço torcido a ter de responder a isso, diria que, pela maior parte do tempo, sou uma pessoa deslocada, que vive com o desejo de construir uma máquina do tempo desde os seus cinco anos. Eventualmente encontrei-a na arte, porque a arte, seja essa qual for, faznos imergir num tempo e num espaço diferentes. Por isso, e constantemente, alimento-me de tempo e de escapismo, seja sentado ao piano, a ler, a desenhar, ... No fundo é uma dependência funcional, uma perfeita fantasia, a de fabricar independentemente a sua própria 
dependência. De resto ocupa-me a psicoterapia há coisa de quinze anos. É essa a minha profissão, mas também a maneira de colocar um ouvido rente ao chão do mundo, e de me manter longe da misantropia e de um tendencioso e fácil eremitério. De resto, tenho como fanatismo o cinema. Cresci no seio de uma família liberal, de músicos, contistas, professores e gosto de me ver como uma continuidade natural disso.

\section{SLMA: Porque escreve?}

$J P P$ : Escrevo sobretudo porque o real não me interessa muito. O real mundano é-me uma morte, e prefiro o simbólico, o sonho, a desconstrução analítica, a construção de realidades plausíveis ainda que alternativas, a criação de gente, e o controlo em fluxo que nos permite a ficção, como que se sentados a um piano a tocar jazz por horas, sem regresso, sem pauta, apenas num automático, como a própria vida. E, depois, escrevo porque não consigo fazer o oposto. Sempre que tento não escrever - e já forcei a mão à quietude muitas vezes - falho. Logo se conjura uma ideia que tem de estar no papel. E sou mais feliz quando escrevo, comprovadamente. Não subscrevo àquela escola de que a escrita é trabalho custoso. Escrevo em fluxo, com extremo verve e alegria, sem revisões, com neologismos e tudo. No fim, adoro aperceber-me das conexões automáticas que se foram fazendo em gerúndio e num inconsciente activo que, entretanto, tomou conta das mãos, dos dedos. Faço o mesmo no piano, e se houvesse uma maneira de transcrever de imediato o que se compõe para a pauta, teria quilómetros de música escrita. Mais, possivelmente, do que contos, romances ou poesia. Mas a escrita é também tocar, é fazer música. O que mais me cativa, à exceção da orgânica, da trama narrativa, das personagens, é a linguagem e a música na escrita. O que me interessa, no fundo, é criar uma nova linguagem, uma nova música, uma voz distinta. O resto é papel de parede. E não gosto de papel de parede.

SLMA: Uma voz distinta em que sentido?

JPP: Apenas no sentido de ser distinguível. De ser claramente a minha e não uma imitação ou uma de mil variações. Isso importa-me. Gosto de saber quem ouço ou quem leio sem ter de passar pela capa ou pela lombada. 
SLMA: Diz que "O real mundano é-me uma morte". Quer explicar melhor este pensamento? De que se alimenta a sua arte, ou seja, os livros que escreve, a música que toca, os desenhos que produz... do imaginário?

$J P P:$ Os livros que escrevo alimentam-se dos livros que leio, a música da música que ouço. Não das narrativas e das vozes, mas dos verbos: ler e ouvir faz escrever e tocar. Mas ao dizer isto apercebo-me de que é tudo uma mescla. Não me lembro de uma altura em que não escrevesse ou lesse ou, pelo menos, ouvisse e fizesse música. Lembro-me de não chegar com os pés aos pedais do piano, e lembro-me de ter um lápis nas mãos mal a motricidade fina arrancou. Nós todos somos compostos pelo nosso fantasmagórico, o nosso mar de interior. A maioria deixa-se comandar por isso sem o saber, sem estar ao leme. O David Lynch famosamente não aderiu à psicoterapia por ter medo de que a análise lhe mitigasse a criação artística. Mas não existe algo impensado, tudo é pensado, ainda que em níveis diferentes. $\mathrm{E}$ a arte, se é para existir, existe, tal como a própria natureza que encontra sempre uma solução de ser. De resto, passamos a adulticidade a replicar ou a tentar resolver a infância. Cresci numa biblioteca, sentaram-me ao colo e deram livros a comer aos meus olhos. $\mathrm{O}$ meu avô colocava no gira-discos os LPs do Villaret no S. Luís, e os Jograis de S. Paulo, e o Yves Montand, e contava-me das suas aventuras em Paris. A minha avó tocava Brahms enquanto eu lhe pousava a cabeça no colo. A minha mãe lia-me estórias, e inventava algumas também. Tudo isso é a tela sobre a qual se pinta a vida. As tintas e as cores vêm depois com a vivência. A minha experiência como psicoterapeuta fez-me escrever $O$ Rochedo que Chorou, uma serigrafia oferecida pelo Mestre Cruzeiro Seixas lançou-me na viagem literária de inundar Lisboa no livro Porta Azul para Macau, o amor pela História, incutido pela minha mãe, deu-me o Alienação, A Brecha foi uma tentativa de contar a evolução do Homem através da metáfora epopeica, e nada me é mais pessoal e íntimo do que os Contos Bizarros.

SLMA: De que forma a sua profissão como psicólogo clínico influencia a sua escrita? Como é que essa influência aconteceu, concretamente, em $O$ Rochedo que Chorou?

JPP: Creio que o amor pela psicanálise, ou pelo menos a paixão desenfreada, deixou-me com um determinado filtro grudado aos olhos e 
que me empurra para o simbólico e para o surreal. Mas antes disso já me achava kafkiano o quanto bastasse. N'O Rochedo que Chorou, um psicoterapeuta transforma-se literalmente numa ilha, contrariando a frase canónica de John Donne. Não creio que a minha escrita fosse a mesma se não tivesse lido Freud, Jung ou Lacan. Mas talvez possa dizer o mesmo quanto a muitos, muitos outros autores.

SLMA: Quando afirma que "passamos a adulticidade a replicar ou tentar resolver a infância", é a voz do psicólogo clínico João Pedro Porto que ouvimos? Como se vê: psicoterapeuta-escritor ou escritor-psicoterapeuta?

$J P P:$ Por esta altura já não há distinção entre partes. O clínico fundiu-se ao escritor e a todas as outras partes. Isso seria como perguntar se a voz agora é a do homem ou da criança, que hoje são o mesmo, um tentando reconciliarse ou adaptar-se ao outro. Um tentando, inclusive, resolver o outro.

SLMA: Curiosamente, na sua primeira resposta, afirma que a psicoterapia lhe permite "colocar um ouvido rente ao chão do mundo". Sente que necessita de ser trazido à realidade também para escrever? Considera-se, por isso, um "escritor-eremita"?

JPP: O eremitério tem apenas que ver com a tendência a rodear-me de fontes de informação. Perco-me nelas, nesse buraco Carrollino com muita facilidade, atrás do coelho branco, sentindo o mesmo atraso que ele. Sinto sempre que não sei o suficiente e que muito falta, e que pouco tempo resta nos comenos curtos da vida. A realidade faz parte necessariamente da vida, e o retorno é um dos seus maiores temas. Distanciar-me dela em demasia seria sinónimo de perdição, de psicose. Creio-me demasiado neurotizado para isso. E tenho encontrado múltiplas formas de exercícios para o equilíbrio, físico e mental. O dia começa sempre com pesos livres, em busca do sol e aço do Yukio Mishima, e, portanto, de um trabalho do domínio da carne, longe das palavras e do efeito corrosivo que têm sobre a realidade; depois algumas horas de escrita, e só depois me dou às horas clínicas. Mas a dada altura perde-se o equilíbrio e toca-se piano ou escreve-se pela noite dentro. A primeira hipótese, sendo a mais desconfortável para os vizinhos. 
SLMA: Como elabora o distanciamento entre fronteiras tão ténues como as que contornam, no seu caso, a psicoterapia e escrita? Como se distancia ou como se apropria destas fronteiras?

JPP: Não quero de todo dar a entender que me divido apenas em duas facções intermitentes, pois isso seria uma mentira demasiado óbvia. Todas as partes do corpo existem no corpo sem verdadeiras fronteiras, e sem transparência, por isso quaisquer limites nunca serão óbvios. Dizemos muitas vezes que há uma fina linha fronteiriça entre isto e aquilo, mas isso é falacioso. Dizemo-lo para não nos confrontarmos com a verdade: que nós é que imaginamos os limites, que eles são construções maleáveis e mutáveis, e que é difícil respeitá-los e ter nisso um equilíbrio. É apenas mais uma forma de controlo falacioso criada para nos regermos. Uma entre tantas. Tenho um código deontológico, tenho um género de regulamento interno que me foi legado na educação, e tenho um conjunto de intenções. Isso basta, creio. Por vezes é demasiado.

SLMA: A sua tese de mestrado aborda, de certa forma, a presença da doença na literatura. Movendo-se pelo mundo da psicologia clínica e da literatura, qual é a importância da literatura ao abordar a temática da doença, um tema que, de certo modo, nos afeta a todos?

$J P P:$ O sofrimento humano é dos componentes maiores a sublimar na arte. Logo, a doença, seja de que etiologia for, estará presente. Para além disso, penso que a construção neurótica é, geralmente, a mais comum na propensão artística, por isso lá estarão as nossas neuroses, as nossas obsessões e a compulsividade de a elas regressarmos e tentarmos partir o bloco de mármore de Carrara até a uma forma que ainda não conhecemos, e que ironicamente nunca iremos conhecer. Mas há um instinto comum de chegar a uma forma, e isso é bonito. Acredito muito que a nossa natureza não é propriamente maravilhosa, mas que muito do que fazemos para a melhorar ou vencer, é. Debrucei-me, por exemplo e a dada altura, sobre a violência na sua forma patológica e, portanto, não natural e evolutiva. A doença é isso. Se a saúde é o que fazemos para contrariar a natureza, e não morrer e sofrer, a doença é o contrário: uma aproximação à morte e ao sofrimento. E colocá-la na página é sublimá-la, e, portanto, sublimar o inevitável - tentar contrariar o inevitável é do mais humano que há. $\mathrm{Na}$ 
literatura sempre houve um fascínio pela doença e pelo doentio, no romance victoriano de deformidades monstruosas, nas distopias, no relato particular... Ocorre-me, por exemplo, A Morte de Ivan Ilyich, de Tolstoy, em que o personagem principal cai, magoa-se e assim inicia uma contenda com a sua própria mortalidade e com a elisão que a doença vai fazendo cair sobre a vida. Ou ainda a criação de doenças fictícias, como n'O Último Homem de Mary Shelley, um dos primeiros romances sobre pandemias, ou n'A Máscara da Morte Vermelha, de Edgar Allan Poe. Sem esquecer o fabuloso A Peste, de Camus.

SLMA: De que forma esta ligação pode esclarecer/ajudar os leitores?

$J P P$ : Não creio que a literatura tenha forçosamente de ajudar ou esclarecer a literatura ficcional, digo - mas se o fizer, creio que por identificação, empatia com a superação ou com o próprio sofrimento. Repare que uma narrativa sobre libertação, um Conde de Monte Cristo, por exemplo, pode fazer maravilhas por alguém que precise de superar uma situação de patologia, ainda que não haja uma correlação directa, salvo pelo tema escapista. Tenho pacientes fóbicos que encontraram um conforto tremendo na alegoria do poço no livro Homens imprudentemente poéticos do Valter Hugo Mãe. Outros que empatizaram assustadoramente com Jean-Dominique Bauby, no seu O Escafandro e a Borboleta. O modo como a literatura nos atinge é quase tão imprevisível quanto a nossa relação com a doença.

SLMA: Recomenda leituras aos seus pacientes?

JPP: O conselho e a recomendação são as armas mais perigosas da humanidade, e em terapia deixo-as para os comportamentalistas e para a sua escola mais pragmática e capitalizável. Recomendo a leitura, sim. Leituras, não, pois nesta tão era de tão acessível informação, acredito que a procura e a escolha são as ferramentas a cultivar nos pacientes e nas pessoas em geral. Uso, claro, todo o material projectivo que me tragam, com total isenção de julgamento, isso sim é próprio deontologicamente. Se pudesse recomendar um Thomas Mann, uma Montanha Mágica ou um Morte em Veneza, nas vertentes da patologia psicossocial e fisiológica, fá-lo-ia. Recomendaria Saramago sem qualquer pudor, Claudio Magris, Umberto Eco, Jorge Luís Borges, Kafka, Calvino, Camus, Verne, ..., até Boris Vian. 
Mas nunca em contexto terapêutico, a não ser que, à partida, fosse o paciente a trazer todo esse conteúdo como parte já do seu fantasmagórico.

SLMA: Da sua experiência, os relatos sobre doença são, regra geral, baseados em casos reais?

JPP: Não necessariamente, pero que las hay las hay. A sublimação, por vezes, é a do escritor. Muitas vezes a narrativa é a ferramenta de quem escreveu e, só depois, do leitor. A psicoterapia, devidamente feita, com um olho na contratransferência e o outro na dança orgânica e analítica das palavras, é o mesmo. Um processo a dois, com convidados evocados pela memória e tratados na relação.

SLMA: Refere na resposta anterior que "A psicoterapia, devidamente feita, com um olho na contratransferência e o outro na dança orgânica e analítica das palavras, é o mesmo." Quer explicar esta ideia, aprofundando as noções de contratransferência, dança orgânica e analítica das palavras?

JPP: Dito de uma maneira simples ou até demasiado simplória: somos criaturas relacionais, que se criam na relação e se reinventam na relação. É essa a nossa essência. Construímo-nos com o outro à medida que construímos o outro. É essa a dança orgânica, e a linguagem é pincel e cinzel nesse trabalho. A acção terapêutica cuidada é feita com as mesmas ferramentas e com os mesmo passos de dança. Ainda hoje creio que a psicoterapia tem mais de arte do que de ciência por essa mesma razão, porque nem todos sabem bem dançar, ou usar o pincel e o cinzel.

SLMA: Refere que nada lhe é mais pessoal e íntimo do que os Contos Bizarros. Por quê?

$J P P:$ Porque são explorações de temas que me são muito particulares, escritos numa altura em que baixei aquela guarda reservada para nos escondermos, ou escondermos o que sentimos. E porque uns foram escritos em inglês e traduzidos para o português e vice-versa, o que acabou por lhes dar uma maior veracidade. Gostava de, um dia, fazer o mesmo com o francês, escrevendo nas três línguas em simultâneo. Creio que isso acaba por colorir o conjunto com cores mais próximas de uma verdade. E acredito 
que estou mais presente nos contos, quer em Contos Bizarros quer em Fruta do Chão, mais do que em qualquer outro escrito.

SLMA: Como sente o desafio da tradução, particularmente, da tradução dos seus textos? Sente-se um traduttore, traditore?

JPP: Ali, tanto nos Contos Bizarros como no Pássaros de Poente, não sinto ter feito uma verdadeira, pura tradução, pois escrevi contos e poemas directamente em inglês, e outros em português, e por vezes porções numa língua e outras noutra; já nem consigo discernir qual foi a língua primária para cada um. Acabei tecendo o que considero dois originais, ou duas versões que se alternam inclusive em símbolos e significados. A fazê-lo canonicamente, seria, suponho, um péssimo tradutor. Aliás, muitas vezes sou crítico de traduções e, se puder, leio o livro na sua língua original. E se tivesse de aprender uma língua nova para isso, seria uma alegria. Para mais, na minha casa sempre falámos em múltiplos registos linguísticos, e ainda hoje, mesmo na interioridade do pensamento, uso ora uma língua ora outra, como numa trança francesa ou um nó de corrente. Uma das coisas em que acredito, é que não devemos relegar a aprendizagem linguística para o lugar da infância apenas pela facilidade neurológica. Devemos, sim, constantemente exercitá-la. E tenho descoberto que um dos grandes marcadores da inteligência humana é a contínua capacidade de entendimento e integração linguística.

SLMA: Podemos falar de interseção das artes nos seus livros?

JPP: Podemos falar, talvez, da dificuldade em simplificar por eliminação, que é um dos meus defeitos. Escrever apenas poesia, apenas prosa, apenas desenhar, e ter apenas pedaços de um cobrejão, não me aquece, e deixa-me sempre os pés de fora. Preciso da manta de retalhos por inteiro, com todas as suas partes. E é-me difícil deixar algo de fora. Quase tão difícil quanto simplificar. Creio que o amor pela simplificação é uma defesa contra a natureza complicada das coisas, e um lugar onde muitos encontram segurança. Prefiro deixar a depuração para a análise, para o depois, para quando estamos no miradouro a ver o cobrejão complicado que entretanto estendemos à nossa frente. Há, evidentemente, espaço para o convívio entre o haiku e o poema épico. E espaço para uma literatura descomplicada 
e até comercial, mas também para aquela cujo ímpeto é o artístico e o experimental. $\mathrm{O}$ que me dizem com maior recorrência é que devo simplificar mais a escrita, mas isso mudaria por completo a sua musicalidade e as imagens que conjuro. Pelo menos defendo-me dessa ideia com esta racionalização, talvez por não gostar de escrever de outro modo. E, como disse, não subscrevo à escola que diz da arte ser labuta dolorosa. Para mim, pelo menos, arte é prazer e sublimação. Nos meus primeiros dois romances, a poesia e os desenhos intercalavam e faziam avançar a prosa; no terceiro, a narrativa era cortada por intertextualidades teatrais; A Brecha é cortada por uma peça de teatro inteira, e acaba com um poema épico que reconta toda a estória; em Alienação, os capítulos são polvilhados com um género de pequenos textos poéticos. $\mathrm{E}$ a maior parte das ilustrações das capas nasceu de rabiscos meus. O primeiro romance tinha inclusive uma peça musical acompanhante, mas essa ficou para a gaveta do esquecimento. E para cada conto faço questão de rabiscar qualquer coisa que, geralmente, depois destruo. $\mathrm{O}$ acto de destruição deve também acompanhar a construção, é saudável que assim o seja.

SLMA: O que refere acerca da interseção que nomeia nos seus livros $A$ Brecha e Alienação, remete-me para uma afirmação sua recente, afirmando que não acredita em géneros literários. Quer explicar esta ideia?

JPP: As ideias de método ou género incomodam-me porque fazem-me pensar em pintura por números ou em puzzles, e isso terá pouco a ver com o processo criativo e mais com truques que possibilitam a reprodução. Criação e reprodução são o mesmo apenas na biologia. Quem se confina a géneros literários e a rótulos não escreve, circunscreve. Limita e enclausurase. E, se pensar muito nisso, chegarei à conclusão que nunca escrevi romances, mas sim vários conjunto de contos a que chamei capítulos, e que nunca escrevi contos, senão resumos organicamente diminuídos de possíveis romances. E que os meus poemas são aforismos, ou exercícios de lógica que tentam ter também alguma beleza. E que o excesso de didascálias nas peças faz com que sejam apenas textos dramáticos. E que as letras musicais não passam de poemas sem sequer sombra de estrutura. E que, portanto, nunca escrevi coisas com rótulos, nem romances, nem contos, nem poemas, ..., nada. Talvez tenha escrito desenhos, e desenhado escritos. E espero ter conseguido fazer música de todos. 
SLMA: A propósito d'O Rochedo que Chorou, Fernando Guimarães afirma que: “a escrita de João Pedro Porto dá-nos uma visão desassombrada da condição humana"1. De que forma o preocupa a condição humana e a (des)humana condição?

JPP: Preocupa-me do modo que nos deve preocupar a todos: muitíssimo. Mais do que nunca, numa altura em que mal acompanhamos a velocidade da mudança, devemos ter essa díade temática sobre a proverbial mesa. Creio que toda a arte dirá algo sobre a condição humana e a sua desumana condição. É essa a condição redundante da expressão humana, mas que não é de todo redundante no seu entendimento. Será sine qua non. Pensemos, por exemplo, em evitar escrever sobre a condição humana, e veremos se é possível. Não creio. Lá estaremos em tudo projectados. Pensemos agora em evitar escrever sobre o sofrimento. A peça sairá satírica e, portanto, contra si mesma e a favor do tema evitado. Não há escapatória. Assim como não devemos escapar à preocupação que isso carrega.

SLMA: Como foi a experiência de ter trabalhado com Pedro Lucas e Carlos Medeiros, escrevendo as letras para os álbuns Terra do Corpo e Sol de Março?

JPP: Foi transformadora, no mínimo. Mudou em muito a sonoridade da minha escrita. Descobri-me um incontornável amante das aliterações e um alérgico à rima. $\mathrm{E}$ colocou-me em maior contacto com os meus temas: $\mathrm{o}$ tempo, a solidão, as pulsões, o descobrimento, a epopeia, ..., todos cristalizaram de tal maneira que me é difícil fugir deles agora, se alguma vez o foi fácil. Trabalhar com o Pedro Lucas tem sido recorrente na sua necessidade, pois encontrámos uma dinâmica que nos permite não parar o fluxo criativo, fazendo-nos dar um empuxo mútuo em épocas dadas ao relantio. E vê-los a actuar, em concertos de pequena e grande dimensão, foi formidável. Sentir toda uma multidão a entoar ou a reverberar ao ritmo da música e das palavras, foi uma das melhores experiências.

SLMA: Açoriano, de formação académica feita fora dos Açores, mas regressado a São Miguel onde a sua escrita tem sido produzida. Escreve

${ }^{1}$ Disponível em: http://partimonio.blogspot.com/2011/11/acerca-de-o-rochedo-que-chorou.html. 
em cenários açorianos, mas também em cenários externos aos Açores. Sente-se das ilhas?

JPP: Nunca fui particularmente regionalista. E o meu desejo de viver o mundo eventualmente foi saciado em inúmeras viagens, sozinho e acompanhado, pelas terras que mais me pareciam falar ao coração. Mais falantes, nesse sentido, do que as minhas. Claro que o tema do regresso importa-me, e é local. Mas procuro não escrever cenários circunscritos a uma geografia, e se o faço, aquela geografia é extremamente ficcionada, quase ao ponto do realismo mágico, ou até mesmo do surrealismo. Sintome das ilhas como me sinto do mundo. Às vezes sinto-me também do meu mundo ficcional, mas suponho que é para isso que ele existe.

SLMA: De que forma a ilha está presenta na sua escrita?

JPP: A ilha está presente na escrita de todo o escritor, seja este oriundo de um deserto e nunca tenha visto o mar, ou tenha nascido no meio do Pacífico. A ilha é uma imagem de solidão no vasto vazio, e isso é-nos comum a todos, mais ainda desde que a terra foi vista do espaço. Dito isto, no primeiro livro que publiquei, o terapeuta era uma ilha, no segundo vivia-se num arquipélago, no terceiro, Lisboa era um conjunto de sete ilhas e não de colinas... e por aí afora, por isso ser-me-ia pretensioso negar que esse tema, que para mim está no cerne de toda a humanidade, não está presente nos meus escritos.

SLMA: Sente-se "Sísifo com a ilha em si e aos ombros", parafraseando o título de Vamberto Freitas ainda a propósito d'O Rochedo que Chorou?

JPP: É uma frase fabulosa. Serei Sísifo de muitas maneiras, creio. Essa, uma. Mas há-que imaginar Sísifo feliz, parafraseando Camus. Todos carregamos coisas aos ombros, nem que seja a cabeça acima deles, ou o próprio mundo como o titã Atlas, mas devemos saber tudo pousar, até a cabeça, sobre o colo da quietude, da contemplação, da realização, ..., e esse por vezes é o acto mais difícil.

${ }^{2}$ Açoriano Oriental. 25 novembro, 2011. 20. 
SLMA: Valter Hugo Mãe considera-o um escritor "cénico, performático, esdrúxulo, temperamental, mas sem arrogância" ${ }^{3}$. Revê-se nas palavras do escritor?

JPP: São palavras enormes de uma pessoa enorme e, portanto, apenas posso dizer que sim. Sei-me esdrúxulo, pois a palavra grudou desde então, e faz-me sempre sentido na contemplação narcísica no Estige. De resto, admiro o Valter Hugo Mãe imensamente, e tenho-lhe uma amizade com a mesma medida, ou mesmo desmedida; devolvo-lhe, inclusive, palavras semelhantes para a sua descrição, e isso deixa-me feliz.

SLMA: Luis António de Assis Brasil escreveu que o João Pedro fala "como um escritor que vai à raiz do humano". Como se processam em si, escritor, e em si, João Pedro Porto, as viagens que Assis Brasil denuncia?

JPP: Assis Brasil é-me uma grande referência, pois preenche ambos os critérios de grande escritor e grande pessoa. Dêem-lhe esta folha que, sobre qualquer coisa que escreva, eu por baixo assinarei, mesmo que elogiosa como a que citou, não terei outra escolha senão subscrever. Dito isto, não sei se a acção será a de ir à raiz ou a de ser alimentado por ela; afinal é essa a função das raízes, e quando nos privamos dessa nutrição, é apenas natural que definhemos. Somos humanos, logo a nossa raiz é a de humanidade, e não somos uma espécie que pegue de galho ou enxertia, temos de cuidar do solo, com a sombra de uma grave penalização se não o fizermos. Tento não me limitar à análise do humano, mas se considerarmos que qualquer outra análise ou visão será feita por olhos humanos, essa acabará por dizer muito sobre quem olha. No fundo, projectamo-nos em tudo. As coisas invademnos e nós invadimo-las. Por isso o humano, tal como o concebemos e percepcionamos, está em tudo. Mas sem querer abandonar de todo o verbo "viajar", esse é um dos temas que mais me é recorrente. Não como literal, mas naquele sentido da viagem evolutiva, do arco que nós como personagens desta grande peça temos de ter. Devemo-lo, não a um confabulado escritor divino, mas à própria peça, ao próprio verbo "actuar" e, por fim, devemo-lo a nós mesmos: um arco evolutivo, uma viagem.

${ }^{3}$ Ípsilon. 1 de junho, 2014. 
SLMA: Este ano faz precisamente 10 anos que publicou o primeiro livro, $O$ Rochedo que Chorou. Ao longo destes 10 anos publicou 9 livros. O que significa esta data para si?

JPP: Essa década contém anos muito felizes. E a escrita trouxe-me muita dessa felicidade. Conheci pessoas extraordinárias, vi-me lido, apreciado, contestado, reconhecido, criticado, abraçado, mas principalmente pude realizar algo que me é inevitável, sem ser frustrado nessa pulsão. E isso é viver verdadeiramente.

SLMA: Gostaria que partilhasse, com algum detalhe, um dos seus livros em termos de estrutura, assunto, a sua escrita propriamente dita...

JPP: Gosto da viagem que $A$ Brecha permite. Na altura talvez a necessidade de escapismo fosse minha, e talvez eu fosse o Homem desiludido com o mundo, a quem nasce a ideia de fuga, e que olha para o rasgo na parede à frente da sua escrivaninha como a fonte de toda a possibilidade, de descoberta, de conquista... No fundo, escrever o livro foi tudo isso. Talvez não houvesse um rasgo na parede, mas na página, feito a caneta e depois posto em cada palavra. De qualquer modo, tudo começa num promontório em Sagres, onde dois mares se unem, e onde um desconhecido surge, nu e desorientado. Dali esse personagem lança-se a uma aventura que o leva até a uma África figurativa, onírica, a um sul do mundo onde tudo é mais real e humano. E nessa viagem, feita com um grupo de companheiros que, entretanto, recruta, encontra ou salva, somos levados também, pelas diferentes fases do desenvolvimento humano. Lembro-me de ser influenciado por um dos primeiros livros que li, As Minas do Rei Salomão, na versão do nosso Eça, mas também por Cervantes, Goethe, Ariosto e Dante. O discurso é quase quinhentista, mas com laivos marcadamente simbólicos e um traço surreal; e toda a narrativa é refeita no final, num poema épico que reconta toda a estória, alterando-a como é apanágio do próprio relato. Os próprios capítulos oferecem-nos diferentes narradores. E a meio, tudo é lancetado por uma peça dramática. É um livro assumidamente difícil, mas espero também que seja recompensador. Nele acreditou Francisco José Viegas quando o editou na Quetzal, e creio que continuo também a crê-lo um dos escritos que mais me importa. 


\section{SLMA: Que podemos esperar para breve?}

JPP: Espero poder adicionar mais uns quantos livros a essa década antes de acabar, ou pelo menos logo a seguir a isso. Estão no prelo vários escritos: um novo romance, um segundo livro de poesia, múltiplos contos, e talvez uma peça. Sei que muitos contos serão tornados capítulos, a peça integrará possivelmente o romance, e os poemas serão soluços que não quero fazer parar, nem com a colher de açúcar nem a suster a respiração.

\section{OBRAS PUBLICADAS}

O Rochedo Que Chorou (romance), Publiçor, 2011.

O 2egundo M1nuto (romance), Letras Lavadas, 2012.

O Homem Da Mansarda (conto), Seixo Publishers, 2014.

Porta Azul Para Macau (romance), Letras Lavadas, 2014.

A Brecha (romance), Quetzal, 2017.

Fruta do Chão/Fruta del Suelo (contos), trad. de Blanca Martin-Calero, Letras Lavadas, 2018.

Contos Bizarros/Odd Tales (contos), trad. de João Pedro Porto, Letras Lavadas, 2019.

Pássaros de Poente (poesia), Letras Lavadas, 2020.

Alienação (romance), Letras Lavadas, 2020.

Recebido em 25 de abril de 2021

Aprovado em 18 de novembro de 2021

Susana L. M. Antunes

Professor Assistente na Universidade de Wisconsin, Milwaukee, EUA. Doutora em Literatura Portuguesa, Brasileira e Africana de Expressão Portuguesa pela Universidade de Massachusetts Amherst, EUA.

Contato: antunes@uwm.edu

(D): https://orcid.org/0000-0003-2681-2173

A Revista Desassossego utiliza a Licença Creative Commons Attribution que permite o compartilhamento do trabalho com reconhecimento da autoria e publicação inicial neste veículo - Attribution-NonCommercial-NoDerivates 4.0 International (CC BY-NC-ND 4.0), e reconhece que os Autores têm autorização prévia para assumirem contratos adicionais separadamente para distribuição não-exclusiva de versão dos seus trabalhos publicados, desde que fique explicitado o reconhecimento de sua autoria e a publicação inicial nesta revista. 